\title{
Evaluating the Mental Health Training Needs of Community-based Organizations Serving Refugees
}

\author{
Jennifer Anne Simmelink \\ Patricia Shannon
}

\begin{abstract}
This exploratory study examines the mental health knowledge and training needs of refugee-serving community based organizations in a Midwestern state. A survey was administered to 31 staff members at 27 community based organizations (CBOs) to assess the ability of staff to recognize and screen for mental health symptoms that may interfere with successful resettlement. Of the 31 respondents $93.5 \%(n=29)$ see refugees with mental health issues and $48.4 \%(n=15)$ assess refugees for mental health symptoms - primarily through informal assessment. Mainstream organizations were more likely than ethnic organizations to have received training related to the mental health needs of refugees. Results indicate that while refugee led CBOs recognize mental health symptoms of refugees they may be less likely to assess mental health symptoms and refer for treatment. Policy recommendations for improving CBO services to refugees are offered.
\end{abstract}

Keywords: Refugees, community based organizations, mental health training, ethnic organizations

\section{INTRODUCTION}

Since the passage of the Refugee Act in 1980, more than 2 million refugees have resettled in the United States (United States Department of Health and Human Services, 2010). By definition, refugees are fleeing chaotic and cataclysmic events (United Nations High Commissioner for Refugees, 2008). Those who flee war and political instability may have faced torture, imprisonment, rape, beatings, witnessed the killing of family members and the destruction of their homes. Many refugees have spent years in refugee camps where conditions can be just as brutal as in the country from which they fled (UNHCR, 2008). As a result of these traumatic experiences, refugees resettling in the United States are at increased risk of post-traumatic stress disorder (PTSD), depression and other psychosocial symptoms (Johnson \& Thompson, 2008). Resettlement stressors such as the lack of English language skills, living wage jobs and affordable housing can exacerbate mental distress (Corvo \& Peterson, 2005) and untreated mental illness in newly arriving refugees can limit successful resettlement (Mitschke, Mitschke, Slater, \& Teboh, 2011; Potocky-Tripodi, 2003). It can be difficult for health or social service professionals who work with refugees to recognize mental health symptoms, make appropriate referrals or treat mental health symptoms because of differences in language and culture (Kirmayer et al., 2011).

Jennifer Anne Simmelink is a Doctoral Candidate and Patricia Shannon, Ph.D., L.P., is an Assistant Professor, both in the School of Social Work at the University of Minnesota in St. Paul, MN. This work was supported by the Minnesota State Refugee Coordinator.

Copyright @ 2012 Advances in Social Work Vol. 13 No. 2 (Summer 2012), 325-339 
The United States provides federal funding to community based organizations (CBOs) and non-governmental organizations (NGOs) to provide support to resettling refugees through a range of social services including job training, English language classes, and assistance with housing. To secure and maintain funding, CBOs must ensure their refugee clients meet federal measures of successful resettlement outcomes including finding stable employment with health insurance, reducing reliance on public welfare, learning English and making progress toward citizenship (Office of Refugee Resettlement, 2010b). Federal guidelines stipulate that funding to CBOs for resettling refugees must be used primarily for employment related activities and mental health services are not included in approved employment related activities, leaving little money left in budgets to address issues like mental health or exposure to trauma and torture (Public Welfare, 2006). In addition, there is little funding for or provision of technical support and training in serving the mental health needs of refugees. Consequently, CBOs may struggle to recognize and meet the mental health needs of resettling refugees, leading to difficulties in successful resettlement. Proper recognition, assessment and treatment of mental health symptoms in newly resettling refugees has the potential to increase successful resettlement outcomes, but CBOs need to be properly trained and supported in this endeavor.

This paper presents findings from an exploratory study of the mental health skills and training needs of staff at mainstream and ethnic CBOs that serve resettling refugees. A better understanding of the training needs of federally funded social service agencies that serve refugees can lead to more targeted and effective technical support.

\section{LITERATURE REVIEW}

\section{Refugees in the United States}

In 2011 56,419 refugees from more than 20 different countries resettled in the United States (United States Department of Health and Human Services, 2012). This number is down from 74,602 in 2009 (United States Department of Health and Human Services, 2010). The primary countries of origin for incoming refugees were Iraq, Burma and Bhutan. Nearly one-half of all incoming refugees resettled in California, Texas, New York, Arizona, Florida or Michigan.

Many refugees resettling in the United States have been living in refugee camps for many years with little access to employment or education (UNHCR, 2008). Many refugees come from rural, agriculture-based communities and have few employment skills that translate to an urban, post-industrial society like the United States. These conditions can further prolong successful resettlement, particularly for older refugees.

\section{Exposure to Trauma and Risk of Mental Health Symptoms}

Refugees, by definition, are fleeing violence, oppression, civil war or, increasingly, famine and natural disasters. Many refugees have been exposed to traumatic events like violence, rape, torture, imprisonment or forced relocation. Exposure to these events increases risk of developing mental health symptoms including PTSD, depression and 
anxiety (Johnson \& Thompson, 2008). As refugees languish in refugee camps for five, ten or even twenty years, the lack of employment or access to adequate education can contribute to mental health symptoms like depression (Johnson \& Thompson, 2008). Even after resettlement in a third country refugees can face long and difficult periods of acculturation. Language barriers, lack of employable skills, lack of transportation, culture shock, generational gaps and isolation can all contribute to difficulties in resettling and exacerbate war-related trauma or resettlement related depression and anxiety (Porter \& Haslam, 2005).

Several studies describe prevalence rates of trauma and torture, as well as symptoms of war and resettlement related mental and emotional distress among refugees. Between 25 and 69\% of Somali and Oromo refugees in the study reported experiencing torture (Jaranson et al., 2004). Karen refugees from camps in Thailand report multiple traumatic experiences including forced relocation, hiding from soldiers in the jungle, missing family members, torture and rape (Cardozo, Talley, Burton, \& Crawford, 2004).

Exposure to these types of traumatic experiences increases the risk of PTSD, depression, anxiety and other mental health issues in resettling refugees. Prolonged exposure to trauma or the experience of multiple traumas is highly correlated with the development of PTSD in refugees. In a meta-analysis of 181 surveys that included 81,000 refugees from multiple countries Steel and colleagues (2009) found rates of PTSD at $30.6 \%$ and rates of major depression at $30.8 \%$. Recent research on the long-term effects of exposure to war trauma and torture indicates that PTSD and depression can be longlasting and debilitating (Carlsson, Olsen, Mortensen, \& Kastrup, 2006; Marshall, Schell, Elliott, Berthold, \& Chun, 2005). Left untreated, these mental health symptoms can prevent stable resettlement (Beiser \& Hou, 2001; Kirmayer et al., 2011; Marshall et al., 2005).

Mental health symptoms that developed during flight and in refugee camps can interfere with successful resettlement in the United States and are often undiagnosed and untreated. Challenges to recognizing mental health symptoms in refugees include language and communication difficulties, cultural differences in health beliefs and behaviors, differences in family structures, intergenerational conflict, and social status (Kirmayer et al., 2011).

Mental and emotional distress from pre-flight and migration as well as from the acculturation process can interfere with successful resettlement in third countries. Often during resettlement war-related trauma is one of several issues facing refugees (Davidson, Murray, \& Schweitzer, 2008). Past trauma is often ongoing because many refugees have left friends and family members behind in home countries or refugee camps. Upon arrival in the United States refugees need to quickly learn a new cultural, legal, social and economic system. At the same time, they are coping with multiple losses of home, family, culture and language. Many refugees experience acute mental health symptoms upon arrival in a resettlement country that decrease over time (Beiser, 1988; Tran, Manalo, \& Nguyen, 2007). Other refugees, frequently those who have experienced higher levels of war trauma, have a greater risk of developing mental health disorders after resettlement (Steel, Silove, Phan, \& Bauman, 2002). 
There is evidence that refugees who have difficulty with acculturation and resettlement have worse resettlement outcomes. These difficulties include changes in social roles (Colic-Peisker \& Walker, 2003), unemployment and financial difficulties (Beiser \& Hou, 2001), and social isolation (Miller et al., 2002; Mollica et al., 2001). In a large meta-analysis Porter and Haslam (2005) found that refugees from countries with continuing or flaring violence and refugees with a marked decrease in social status after resettlement did worse in terms of markers of successful resettlement than refugees who resettled with material security and stable housing.

Mental health symptoms, if left untreated, can continue to interfere with resettlement even decades later. In a study of 568 Cambodian adults interviewed two decades after resettlement, Marshall et al. (2005) found that refugees continued to have high rates of PTSD (62\%, weighted) and depression (42\%, weighted). In addition, the study found that people who are older, have low English language proficiency, are unemployed or are poor have higher levels of PTSD and depression.

\section{Supporting Successful Refugee Resettlement}

The United States recognizes the unique needs of resettling refugees and US refugee admission policies have been adapted to provide funding for resettlement-related social services. The Refugee Act of 1980, which created the first permanent statutory basis for refugee admissions, also created the Office of Refugee Resettlement (ORR), a department of the US Department of Health and Human Services (HHS). The US Department of State allocates funds annually based on refugee admission numbers to ORR. The ORR then awards these funds to states through grants to community based agencies that provide resettlement services including reception, housing, employment, English language training and education. In fiscal year 2010 ORR awarded a total of \$171 million in discretionary grants (Office of Refugee Resettlement, 2010a).

To receive grants through ORR, CBOs must demonstrate that they have met certain outcome goals related to refugee economic self-sufficiency. These goals include ensuring a significant number of resettling refugees enter employment, remain employed for 90 days or longer, reduce or terminate their reliance on cash assistance, and receive health benefits through full-time employment (ORR, 2010). This heavy emphasis on employment-related activities can prevent agencies from having time and resources to address mental health symptoms related to war trauma, torture or the stress of resettlement that may interfere with employment.

\section{Development and Focus of Ethnic Community Based Organizations}

Ethnic community based organizations, often called mutual assistance agencies (MAAs) in the academic literature, have a long history in the United States and the US has long relied on ethnic community based organizations to provide social services and to support incoming refugees (Hein, 1997). Ethnic solidarity theories (Breton, 1964) posit that these organizations provide a base for leadership, welcome and support newcomers through employment and financial resources, and facilitate successful resettlement (Hein, 1997). Ethnic solidarity theory has been challenged by research that indicates immersion 
in ethnic communities has a negative long-term impact on refugees' economic selfsufficiency (Majka \& Mullen, 2002). Ethnic organizations may lack access to mainstream resources making it more difficult for refugees to achieve self-sufficiency. In addition, by providing federal funding with specific criteria about how the money should be spent and on what, the federal government ends up setting priorities for ethnic communities that may not match their needs. For example, funding may prioritize employment-related activities, channeling an organization's efforts towards training rather than other services, including mental health services (Hein, 1997).

While ethnic organizations provide essential supportive services for refugees, particularly in the first few months of resettlement, by accepting federal resettlement funds, their programs become significantly limited to government-determined outcomes. The omission of mental health services from federal definitions of successful refugee resettlement means ethnic organizations are less likely to provide these services. Training and technological support from the federal government also focuses on employment related services, meaning ethnic organizations are less likely to receive training in recognizing and addressing mental health issues in refugees. Although ethnic led CBOs might recognize the effects of trauma in refugees, they may lack the knowledge and resources to address these issues.

Untreated mental health symptoms interfere with meeting the outcomes outlined by the federal government in defining successful resettlement. CBOs and refugee social service agencies lack training to provide support for refugees with mental health symptoms. Refugees who struggle with mental health symptoms long after resettlement are at risk of ending up on long-term disability. Research indicates that early intervention can significantly reduce the risk of long-term mental health symptoms such as posttraumatic stress disorder (Foa, Keane, Friedman, \& Cohen, 2009). Providing CBOs with training and material support to address refugees' mental health needs may significantly improve resettlement outcomes.

\section{METHOD}

This study is an exploratory examination of the mental health skills and training needs of mainstream and ethnic community based organizations that serve refugees. The purpose of the survey was to determine if community based organizations are serving refugee clients with mental health issues and if so, to assess the knowledge and ability of staff to recognize and screen for trauma-related mental health symptoms that may interfere with the successful resettlement of refugees.

\section{Sample}

This study uses a convenience sample of 31 staff members at 27 community based organizations that have contracts with the Office of Refugee Resettlement to provide services to refugees in a Midwestern state. In 2009 the ORR provided formula or discretionary grants to about 70 CBOs in this state. The survey was given at a quarterly meeting of agencies convened by the Office of Refugee Resettlement. The survey was introduced and endorsed by the State Refugee Coordinator as part of a community based 
needs assessment and was exempt from institutional review board approval. Job titles of individuals completing the survey included program manager, executive director, staff attorney, and direct service personnel. The sample favors metro-based organizations; however, some rural organizations are represented.

\section{Survey Instrument}

The survey was designed by the authors and self-administered via pencil and paper. Participation in the survey was not mandatory and information about organizations that were present at the meeting but chose not to complete the survey was not collected. Identifying information including name of the person filling out the survey and job title was collected with the survey. Respondents took about 20 minutes to complete the survey.

The survey contained primarily yes/no questions including: "Do you ask your clients if they have been exposed to war trauma or torture in their home countries?”, "Do you see clients who suffer with mental health or stress related problems that affect their ability to successfully adjust to living in the United States?", "Does your agency assess clients for mental health problems or symptoms either formally through a questionnaire or informally through conversation?", "Would you find it useful to have a tool for identifying mental health symptoms that your clients struggle with?”.

Three questions asked about referring clients for treatment for mental health issues. First, respondents were asked: "Do you refer clients to other agencies for assistance with treatment of mental health symptoms?" Next, respondents were asked to rate their clients' success at connecting with those referrals on a Likert scale of 0 (Not at all successful) to 3 (Always successful). Finally, respondents were asked to list any barriers their clients experience when trying to access services for mental health concerns.

Three questions asked about training related to the mental health needs of refugees. First, respondents were asked: "Has your agency received any training on serving the needs of war trauma/torture survivors?" Second, respondents were asked to rate how knowledgeable their staff is in understanding and serving the needs of war trauma and/or torture survivors on a Likert scale from 0 (Not at all knowledgeable) to 3 (Extremely knowledgeable). Third, respondents were asked to rate their interest in receiving training or consultation for their agency staff on specific topics related to torture and war trauma on a Likert scale from 0 (Not at all interested) to 3 (Extremely interested). Respondents were given space to add additional written comments after each question and were given space at the end to write additional thoughts, comments or suggestions.

\section{Analysis}

Because this is an exploratory study and data is limited, descriptive statistics and crosstabs were performed. Analysis was completed using Stata statistical software, version 11. Responses were analyzed in two ways. First, responses were aggregated and analyzed as a whole. Second, responses were categorized by organization type. Organizations that responded to the survey were divided into two categories: mainstream community based organizations (CBOs) and ethnic community based organizations. 
Mainstream CBOs were defined as community-based non-profit or government agencies/departments established for purposes other than refugee resettlement but that now provide significant services to refugees. These include schools, legal services, housing services, voluntary resettlement agencies and other social service agencies. Ethnic-led CBOs are community-based non-profit organizations that were founded by and are run by refugee communities to provide social services to resettling refugees.

\section{FINDINGS}

\section{Demographics}

The sample included 31 respondents from a total of 27 organizations; 13 mainstream community based organizations were represented and 13 ethnic organizations were represented. One respondent did not identify their organization. The 31 respondents were evenly split between the organizations with 15 respondents from mainstream organizations and 15 from ethnic organizations. Table 1 outlines descriptive statistics of responses to the survey.

Table 1: Description of Survey Sample $(n=31)$

\begin{tabular}{|c|c|c|}
\hline Organization Demographics & $\mathbf{n}$ & $\%$ \\
\hline Mainstream CBO & 15 & $50.0 \%$ \\
\hline Ethnic CBO & 15 & $50.0 \%$ \\
\hline No Response & 1 & $3.3 \%$ \\
\hline \multicolumn{3}{|l|}{ Mental Health } \\
\hline See clients with mental health symptoms & 29 & $93.5 \%$ \\
\hline Ask about exposure to trauma/torture & 18 & $58.0 \%$ \\
\hline Assess mental health symptoms & 15 & $48.4 \%$ \\
\hline Culturally valid screening tool would be useful & 27 & $87.0 \%$ \\
\hline \multicolumn{3}{|l|}{ Referrals } \\
\hline Refer for mental health treatment & 23 & $74.2 \%$ \\
\hline Rated likely or extremely likely to connect with referrals ( $n=23$ ) & 17 & $74.0 \%$ \\
\hline \multicolumn{3}{|l|}{ Knowledge and Training } \\
\hline Have received mental health training & 11 & $35.5 \%$ \\
\hline $\begin{array}{l}\text { Rated knowledgeable or extremely knowledgeable about serving } \\
\text { war trauma survivors }(\mathrm{n}=27)\end{array}$ & 12 & $44.0 \%$ \\
\hline Rated interested or extremely interested in training $(n=24)$ & 21 & $88.0 \%$ \\
\hline
\end{tabular}




\section{Assessing War-related Mental Distress}

Overall, 93.5\% $(n=29)$ of respondents see clients with mental health symptoms while $58 \%(n=18)$ ask clients about exposure to trauma or torture and $48.4 \%(n=15)$ assess for mental health symptoms either with a standardized questionnaire or through informal conversation.

\section{Need for a Culturally Grounded Mental Health Screening Tool}

Respondents were asked if they would find it useful to have a culturally relevant tool for identifying mental health symptoms in their clients. Eighty-seven percent $(n=27)$ of respondents indicated that a tool would be useful. The majority of respondents who indicated they currently assess clients for mental health symptoms reported doing so through either informal conversation or with the state's TANF program self-report questionnaire. The questionnaire is a self-report depression screening tool used with the state's application package for TANF grants. This tool was not designed for use with refugees and is not cross-culturally validated.

\section{Referring Clients for Treatment}

Respondents were asked about referral practices. Twenty-three (74.2\%) CBOs refer their clients for treatment for mental health symptoms. Respondents were asked to rate their clients' success at connecting with these referral agencies on a scale of 0 (Not at all likely to connect with referrals) to 3 (Extremely likely to connect with referrals). Seventeen (74\%) agencies reported their clients are likely or extremely likely to connect with referral services.

Nineteen respondents identified barriers to accessing stable psychosocial treatment. This was a short answer question and most participants gave multiple responses. Nine respondents (47.4\%) identified a lack of interpreters or linguistically appropriate provides as a barrier to accessing treatment. Nine (47.4\%) respondents identified stigma as a significant barrier. Five (26.3\%) respondents identified cultural differences in definitions and treatment of mental health symptoms as a barrier. Other barriers listed included lack of transportation $(n=5,26.3 \%)$, cost or lack of health insurance $(n=3,15.8 \%)$, lack of culturally appropriate treatment or providers $(n=3,15.8 \%)$, and difficulty navigating complicated mental health systems $(n=3,15.8 \%)$.

\section{Knowledge and Training}

Eleven respondents (35.5\%) reported received training related to serving refugees with war trauma/torture exposure. Respondents were asked to rate their knowledge of serving the needs of war trauma/torture survivors on a Likert scale of 0 (No knowledge at all) to 3 (Extremely knowledgeable). Twenty-seven respondents answered this question and $44 \%(\mathrm{n}=12)$ reported they are knowledgeable or extremely knowledgeable about serving the needs of war trauma/torture survivors.

Twenty-four organizations rated their interest in receiving training about serving refugees with war-related mental health symptoms on a scale of 0 (Not at all interested) 
to 3 (Extremely interested). Twenty-one (88\%) reported they are interested or extremely interested in receiving training.

\section{Differences between Mainstream and Ethnic CBOs}

Crosstabs show areas where differences may exist in responses between mainstream and ethnic CBOs. These crosstabs indicate areas for further study. Mainstream CBOs may be more likely than ethnic CBOs to want a tool for identifying mental health symptoms that clients struggle with. Mainstream CBOs may be more likely to refer clients for mental health treatment. Mainstream organizations may be more likely to have received training on serving the needs of war trauma/torture survivors. It is important to note that these differences are not statistically significant and simply point out areas for future investigation, rather than real differences. Table 2 below displays differences between mainstream and ethnic CBOs in this particular study.

Table 2: $\quad$ Differences between Mainstream and Ethnic CBOs

\begin{tabular}{lrr}
\hline & $\begin{array}{r}\text { Mainstream CBO } \\
{[\%(\mathbf{m})]}\end{array}$ & $\begin{array}{r}\text { Ethnic CBO } \\
\text { [\% (n)] }\end{array}$ \\
\hline Ask clients about exposure to trauma/torture & $78.6 \%(11)$ & $53.3 \%(8)$ \\
Assess mental health symptoms & $53.3 \%(8)$ & $46.7 \%(7)$ \\
Would like a culturally validated screening tool & $100 \%(15)$ & $73.3 \%(11)$ \\
Refer clients for mental health treatment & $92.9 \%(13)$ & $60 \%(9)$ \\
Have received training & $53.3 \%(8)$ & $13.3 \%(2)$ \\
\hline
\end{tabular}

Note. Overall N for Mainstream CBO $=15$ and for Ethnic CBO $=15$.

Mainstream and ethnic organizations also identified different types of barriers to successfully connecting to mental health services. Eight mainstream organizations identified refugees' stigma against mental illness as a barrier to successfully connecting with referral resources whereas ethnic CBOs did not identify this issues as a barrier. Mainstream organizations cited language issues, transportation, fear, lack of culturally appropriate providers and lack of knowledge about how the mental health system works as the primary barriers to accessing services. Ethnic organizations listed language, lack of culturally appropriate providers and cultural differences in refugees' perceptions of mental illness and treatment as the primary barriers to accessing services.

\section{Short Answer Responses}

Each question allowed space for respondents to write short answer comments and there was space at the end of the survey for additional thoughts or comments. Respondents were also asked to write short answer responses to the type of assessment tool they used for screening refugees for mental health issues and to the barriers that their refugee clients might face when trying to access services for mental health treatment. 
These responses were analyzed thematically, making note of both similarities and frequencies of responses as well as anomalies or disparate responses. Three themes emerged in these comments: identification of training needs, lack of culturally appropriate referral services, and specific barriers to accessing treatment for mental health symptoms.

Although the survey did not ask for written comments in the questions about training needs both in this section and in the general comments section multiple organizations mentioned training needs as being a salient issue. One agency commented that a culturally grounded mental health assessment tool would be helpful "if staff are trained [to use the tool] and can take next steps”. Four organizations that had received training in the past commented that it was several years ago and while they appreciated the knowledge, they felt they needed more. In the general comments section of the survey three organizations commented that they were seeing growing numbers of refugees in their areas and needed training to address their specific needs. One of the respondents wrote "In our community we have a growing Somali and Sudanese refugee population and we basically have no culturally competent referral system. I would love to be a part of any upcoming trainings on mental health.”

\section{DISCUSSION}

This study explores whether CBOs who serve resettling refugees see clients with war-related mental health issues and whether or not they have adequate training and knowledge to assess and refer refugees for mental health issues. Results indicate that most of the respondents do see refugees with war-related mental distress at their agencies. However, only about half of respondents' agencies actually assess refugees for mental health issues and when they do, they use informal conversation rather than a standardized instrument. While many organizations refer refugees to treatment for mental health issues, they identify significant barriers to successfully connecting with those referral services. There appears to be a strong interest in having a culturally relevant, brief, accessible screening tool for assessing mental health issues, and training on refugee mental health issues is needed. Few agencies, particularly ethnic agencies have received training on refugee mental health issues, and perceived knowledge of how to meet refugees' mental health needs is low.

Study results indicate some significant differences between mainstream and ethnic organizations. Mainstream organizations are more likely to refer clients to treatment for mental health issues, more likely to have received training on refugee mental health issues, more likely to want a culturally relevant tool to assess refugee mental health issues, and more likely to name stigma as a barrier for refugees to receiving mental health treatment. The commonly held belief that mental health stigma prevents refugees from connecting with services was not confirmed by the ethnic CBOs in this survey.

These findings are not surprising given the structure of federal funding for refugee resettlement services. Guidelines for federal refugee resettlement funds focus primarily on employment-related activities and leave little room for programs or activities that

address mental health issues. While the Office of Refugee Resettlement has committed 
funding for training CBOs to meet employment-related needs of refugees, little commitment has been made to training organizations to recognize and address symptoms of war related mental distress that may interfere with obtaining and retaining employment. By earmarking most of federal resettlement funds for employment-related activities, federal guidelines significantly influence the focus and programmatic planning of refugee-serving CBOs.

Despite the fact that refugee led CBOs recognize mental health symptoms that their clients are struggling with, ethnic CBOs are less likely to have received training, less likely to refer their clients to mental health services, and less likely to want a culturally relevant tool for assessing mental health issues. This is not surprising considering ethnic CBOs are less likely to be connected to mainstream resources and agencies from which mental health training typically comes and may be unaware that treatment resources exist to help their clients. The competitive nature of federal grants for resettlement services makes it difficult for mainstream and ethnic CBOs to be motivated to collaborate and share their unique knowledge with each other (Majka \& Mullen, 2002).

Mainstream organizations are more likely to have had training but this does not significantly impact their perception of agency knowledge. It is clear that more training is needed for both mainstream and ethnic organizations. However, this training cannot be a "one-size-fits-all" model. Ethnic organizations have specific training needs, as do mainstream organizations. Mainstream organizations might have more training and access to mental health resources, but less knowledge of cultural expressions of distress and language ability. Ethnic organizations may be well-steeped in cultural knowledge but lack information about mental health issues and resources. Training programs need to be targeted to the specific needs of each type of organization.

\section{Implications for Policy and Practice}

The findings of this exploratory study have a number of implications for refugee resettlement policies and for social work practice with refugees. Federal funding for resettlement services prioritizes employment and employability as a primary indicator of successful and stable resettlement. Research on the traumatic experiences and related mental health symptoms of refugees that are currently resettling in the US indicates such symptoms are likely to interfere with successful resettlement for a significant portion of new arrivals (Carlsson et al., 2006). Unrecognized and untreated mental distress in refugees could be a significant barrier to gaining and maintaining stable employment. Addressing refugees' mental health needs in the initial stages of resettlement could lead to more robust resettlement outcomes. This is only possible if there are funds available to support the requisite training and referral needs of CBOs that work with resettling refugees. Federal funds could be earmarked for a more broad definition of employmentrelated activities to allow funding to be spent on mental health programs connected to employment success.

Social work practitioners who work with refugees are uniquely positioned to provide training and referral resources to CBOs. There is a significant shortage of trained social workers from refugee communities. If more people from refugee communities are 
recruited and trained in meeting the mental health needs of resettling refugees they could effectively integrate evidence based models of care with culturally competent practice at both mainstream and ethnic CBOs.

Finally, there appears to be a missing link between ethnic and mainstream CBOs. Mainstream CBOs with long histories in social services may have significant knowledge and awareness of general mental health issues, but lack the cultural grounding or training in recognizing those symptoms in refugees from non-Western backgrounds. Conversely, ethnic organizations are uniquely positioned to serve refugees from a culturally grounded and linguistically relevant base but lack access to and knowledge of mainstream mental health resources. Both types of organizations may stand to gain significantly by learning from each other.

\section{Study Limitations}

This study was limited by the small sample size and the exploratory nature of the survey. About half of the total number CBOs receiving ORR funding in this state are represented, giving a low response rate which further limits the study. Sophisticated statistical analysis of results is limited. The use of a convenience sample of participants in a quarterly meeting also limits the study. Some of the organizations represented in the study are large with multiple departments and staff. To gain a more full understanding of the training needs of an entire organization, this survey would need to be administered to more than one representative from more than one department. Despite these limitations the study points to the need for targeted training for CBOs that work with refugees at risk of war-related mental health symptoms.

\section{Future Research}

Research about the mental health training needs of mainstream and community based organizations serving refugees is limited. Research needs to focus on a better understanding of the unique training needs of ethnic community based organizations as well as mainstream organizations. Research and programs that foster communication and interaction between mainstream and ethnic community based organizations is needed. A better understanding of the variability in training needs within organizations, particularly large organizations with multiple departments and programs, could foster more targeted and effective training programs.

Many CBOs report a need for brief, culturally relevant mental health screening tools, indicating a need for future research on the development and utility of such tools. CBOs would also need training and support in using these tools as well as support in referring and following up with refugees who screen positive for mental health symptoms. Research is needed to understand how to best support both ethnic and mainstream CBOs in successfully using mental health screening tools and referral resources to maximize resettlement outcomes. 


\section{References}

Beiser, M. (1988). Influences of time, ethnicity, and attachment on depression in Southeast Asian refugees. American Journal of Psychiatry, 145, 46-51.

Beiser, M., \& Hou, F. (2001). Language acquisition, unemployment and depressive disorder among Southeast Asian refugees: A 10-year study. Social Science \& Medicine, 53, 1321-1334.

Breton, R. (1964). Institutional completeness of ethnic communities and the personal relations of immigrants. American Journal of Sociology, 70(2), 193-205.

Cardozo, B. L., Talley, L., Burton, A., \& Crawford, C. (2004). Karenni refugees living in Thai-Burmese border camps: traumatic experiences, mental health outcomes, and social functioning. Social Science \& Medicine, 58(2), 2637-2644.

Carlsson, J. M., Olsen, D. R., Mortensen, E. L., Kastrup, M. (2006). Mental health and health-related quality of life: A 10-year follow-up of tortured refugees. Journal of Nervous and Mental Disease, 194(10), 725-731.

Colic-Peisker, V., \& Walker, I. (2003). Human capital, acculturation and social identity: Bosnian refugees in Australia. Journal of Community and Applied Social Psychology, 13, 337-360.

Corvo, K., \& Peterson, J. (2005). Post-traumatic stress symptoms, language acquisition, and self-sufficiency: A study of Bosnian refugees. Journal of Social Work, 5(2), 205219.

Davidson, G. R., Murray, K. E., \& Schweitzer, R. D. (2008). Review of refugee mental health and wellbeing: Australian perspectives. Australian Psychologist, 43, 160-174.

Foa, E. B., Keane, T. M., Friedman, M. J., \& Cohen, J. A. (2009). Effective treatments for PTSD: Practice guidelines from the international society for traumatic stress studies. New York: The Guilford Press.

Hein, J. (1997). Ethnic organizations and the welfare state: The impact of social welfare programs on the formation of Indochinese Refugee Associations. Sociological Forum, 12(2), 279-295.

Jaranson, J. M., Butcher, J., Halcon, L., Johnson, D. R., Robertson, C., Savik, K., ... Westermeyer. J. (2008). Somali and Oromo refugees: Correlates of torture and trauma history. American Journal of Public Health, 94(4), 591-598.

Johnson, H., \& Thompson, A. (2008). The development and maintenance of posttraumatic stress disorder (PTSD) in civilian adult survivors of war trauma and torture: A review. Clinical Psychology Review, 28(1), 36-47.

Kirmayer, L. J., Narasiah, L., Munoz, M., Rashid, M., Ryder, A. G., Guzder, J., \& ... Pottie, K. (2011). Common mental health problems in immigrants and refugees: General approach in primary care. Canadian Medical Association Journal, 183(12), E959-E967. 
Majka, L., \& Mullan, B. (2002). Ethnic communities and ethnic organizations reconsidered: South-east Asians and Eastern Europeans in Chicago. International Migration, 40(2), 71-92.

Marshall, G., Schell, T., Elliott, M., Berthold, S., \& Chun, C. A. (2005). Mental health of Cambodian refugees two decades after resettlement in the United States. Journal of the American Medical Association, 294(5), 571-579.

Miller, K. E., Weine, S. M., Ramic, A., Brkic, N., Bjedic, Z. D., Smajkic, A., ... Worthington, G. (2002). The relative contribution of war experiences and exilerelated stressors to levels of psychological distress among Bosnian refugees. Journal of Traumatic Stress, 15, 377-387.

Mitschke, D. B., Mitschke, A. E., Slater, H. M., \& Teboh, C. (2011). Uncovering health and wellness needs of recently resettled Karen refugees from Burma. Journal of Human Behavior in the Social Environment, 21(5), 490-501.

Mollica, R. F., Sarajlic, N., Chernoff, M., Lavelle, J., Vukovic, I. S., \& Massagli, M. (2001). Longitudinal study of psychiatric symptoms, disability, mortality, and emigration among Bosnian refugee. Journal of the American Medical Association, 286, 546-554.

Office of Refugee Resettlement. (2010a). 2010 Year in Review. Retrieved from http://www.acf.hhs.gov/programs/orr/whatsnew/ORR Year in Review.pdf

Office of Refugee Resettlement. (2010b). Policy guidance and reporting forms. Retrieved from http://www.acf.hhs.gov/programs/orr/policy/gpra_inst.htm

Porter, M., \& Haslam, N. (2005). Predisplacement and postdisplacement factors associated with mental health of refugees and internally displaced persons: A metaanalysis. Journal of the American Medical Association, 294, 602-612.

Potocky-Tripodi, M. (2003). Refugee economic adaptation. Journal of Social Service Research, 30(1), 63-91.

Public Welfare, 45 C.F.R. pt. 400 (2006).

Steel, Z., Chey, T., Silove, D., Marnane, C., Bryant, R. A., \& van Ommeren, M. (2009). Association of torture and other potentially traumatic events with mental health outcomes among populations exposed to mass conflict and displacement: A systematic review and meta-analysis. Journal of the American Medical Association, 302(5), 537-549.

Steel, Z., Silove, D., Phan, T., \& Bauman, A. (2002). Long-term effect of psychological trauma on the mental health of Vietnamese refugees resettled in Australia: A population-based study. The Lancet, 360, 1056-1062.

Tran, T. V., Manalo, V., \& Nguyen, V. T. D. (2007). Nonlinear relationship between length of residence and depression in a community-based sample of Vietnamese Americans. International Journal of Social Psychiatry, 53, 85-94. 
United Nations High Commissioner for Refugees. (2008). Global report. Retrieved from http://www.unhcr.org/pages/49c3646c4b8.html

United States Department of Health and Human Services. (2010). Office of Refugee Resettlement: Data. Retrieved from

http://www.acf.hhs.gov/programs/orr/data/index.htm

United States Department of Health and Human Services. (2012). Office of Refugee Resettlement: Data. Retrieved from

http://www.acf.hhs.gov/programs/orr/data/index.htm

\section{Author Note:}

Address correspondence to: Jennifer Simmelink, MSW, School of Social Work, University of Minnesota, 1404 Gortner Avenue, 105 Peters Hall, St. Paul, MN 55108.

Email: simm0055@umn.edu 